\title{
PENGARUH PENGGUNAAN GADGET TERHADAP KEJADIAN MIOPIA PADA ANAK USIA SEKOLAH (4-17 TAHUN) DI POLI MATA RUMAH SAKIT ISLAM JEMURSARI SURABAYA
}

\author{
Nadia Nisaussholihah $^{1}$, R.A. Hani Faradis ${ }^{2}$, Andi Roesbiantoro ${ }^{3}$, David Sajid Muhammad ${ }^{1}$, Hotimah Masdan \\ Salim $^{4 *}$ \\ ${ }^{1}$ Fakultas Kedokteran, Universitas Nahdlatul Ulama Surabaya \\ ${ }^{2}$ Departemen Penyakit Mata, Fakultas Kedokteran, Universitas Nahdlatul Ulama Surabaya dan Rumah \\ Sakit Islam Jemursari, Surabaya \\ ${ }^{3}$ Departemen Telinga Hidung Tenggorok, Fakultas Kedokteran, Universitas Nahdlatul Ulama Surabaya dan \\ Rumah Sakit Islam Ayani, Surabaya \\ ${ }^{4}$ Departemen Biokimia Kedokteran, Fakultas Kedokteran, Universitas Nahdlatul Ulama Surabaya \\ Correspondent author*: dr.hotimah@unusa.ac.id
}

\section{ABSTRAK}

Pendahuluan: Kelainan refraksi merupakan gangguan penglihatan terbanyak diseluruh dunia, diantara kelainan refraksi tersebut yang paling sering dijumpai adalah miopia. Miopia dapat disebabkan oleh faktor genetik maupun faktor lingkungan, salah satunya dengan melakukan aktivitas melihat dekat seperti menggunakan gadget. Penggunaan gadget dimasa sekarang ini sangat dibutuhkan dalam kehidupan sehari-hari. Setidaknya 30 juta anak-anak dan remaja di Indonesia menggunakan media digital sebagai pilihan utama saluran komunikasi yang mereka gunakan. Tujuan penelitian ini adalah untuk Menganalisis adanya pengaruh penggunaan gadget meliputi posisi, jarak, lama penggunaan, dan pencahayaan ruang terhadap kejadian miopia pada anak usia sekolah (4-17 tahun). Metode Pelaksanaan: Penelitian yang dilakukan bersifat survey analitik dengan pendekatan cross sectional. Populasi penelitian ini adalah pasien anak usia sekolah (4-17 tahun) di Poli Mata Rumah Sakit Islam Jemursari Surabaya yang bersedia dilakukan penelitian dengan jumlah sampel 31 orang. Sampel diambil secara purposive sampling dengan teknik pengambilan data menggunakan kuesioner dan rekam medis responden. Analisis dilakukan dengan menggunakan uji regresi logistik ordinal. Hasil dan Pembahasan: Berdasarkan hasil penelitian sebagian besar menggunakan posisi duduk (61,3\%), menggunakan jarak $\geq 30 \mathrm{~cm}(54,8 \%)$, dengan durasi selama $\geq 2$ jam (54,8 \%), dan menggunakan pencahayaan ruang yang redup (51,6\%). Sebagian besar responden memiliki visus miopia ringan (54,8 \%). Berdasarkan analisis uji regresi logistik ordinal ada pengaruh jarak saat menggunakan gadget terhadap kejadian miopia $(p=0,049)$. Tidak terdapat pengaruh posisi tubuh, lama penggunaan, dan pencahanyaan ruang saat menggunakan gadget terhadap kejadian miopia yang signifikan secara statistik ( $p=0,339 ; p=0,239 ; p=0,301)$. Kesimpulan: Hanya variabel jarak yang memiliki pengaruh yang signifikan secara statistik terhadap kejadian miopia, sedangan untuk variabel posisi tubuh, lama penggunaan, dan pencahayaan ruang tidak memiliki pengaruh yang signifikan.

Kata Kunci: Gadget, Miopia, Anak Usia Sekolah

\section{ABSTRACT}

Background: Refractive disorders are the most common visual disturbances in the entire world, among which the most common refractive disorders are myopia. Myopia can be caused by genetic or environmental factors, one of which is by doing close viewing activities such as using a gadget. The use of gadgets in the present is needed in everyday life. At least 30 million children and adolescents in Indonesia use digital media as the main choice of communication channels they use. The purpose of this study is to analyze the influence of the use of gadgets including position, distance, duration of use, and space lighting on the incidence of myopia in school-age children (4-17 years). Method: The research was analytic survey with a cross sectional approach. The population of this study was school-age children (4-17 years) at the Jemursari Islamic Hospital Surabaya Eye Clinic who were willing to do research with a sample of 31 people. Samples were taken by purposive sampling with data collection techniques using questionnaires and respondent's medical records. The analysis was carried out using ordinal logistic regression tests. Results: Based on the results of the study, most of them used a sitting position (61.3\%), using a distance of $\geq 30 \mathrm{~cm}$ (54.8\%), with a duration of $\geq 2$ hours (54.8\%), and using dim room lighting $(51,6 \%)$. Most of the respondents 
had mild myopia vision (54.8\%). Based on the analysis of ordinal logistic regression there is an effect of distance when using gadgets on the incidence of myopia $(p=0.049)$. There was no effect on body position, duration of use, and space questioning when using gadgets on the incidence of myopia which was statistically significant ( $p=0.339 ; p=0.239 ; p=0.301)$. Conclusion: Only distance variables have a statistically significant influence on the incidence of myopia, while for variables body position, duration of use, and space lighting do not have a significant effect.

Keywords: Gadgets, Myopia, School-Age Children

\section{LATAR BELAKANG}

Mata merupakan indera penglihatan yang sangat penting dalam meningkatkan kualitas hidup manusia sebab berbagai informasi visual diserap oleh mata yang digunakan untuk melaksanakan berbagai kegiatan. Namun gangguan penglihatan banyak terjadi, seperti gangguan penglihatan, katarak dan glukoma. Berdasarkan Global Data on Visual Impairment 2010, WHO 2012 penyebab gangguan penglihatan terbanyak diseluruh dunia adalah gangguan refraksi (42\%) yang tidak terkoreksi, diikuti dengan katarak (33\%) dan glukoma (18\%) (RI, 2014). Menurut Dirjen BUK (Bina Upaya Kesehatan), sebanyak $15 \%$ dari kelainan refraksi diderita oleh anak usia sekolah dan kondisi ini sangat bermasalah serta diperlukan perhatian khusus pada anak-anak usia sekolah (Kementrian Kesehatan RI, 2012). Diantara kelainan refraksi tersebut yang paling sering dijumpai adalah miopia. Kejadian miopia yang terus meningkat dalam 50 tahun terakhir diperkirakan sudah mengenai 1,6 miliar penduduk di seluruh dunia (Yu, et al., 2011).

Smartphone merupakan salah satu barang elektronik yang memiliki kegunaan khusus atau biasa yang kita sebut dengan gadget. Peningkatan penggunaan smartphone di era sekarang ini menimbulkan kekhawatiran pada masyarakat tentang efek negatif radiasi sinar smartphone terhadap kesehatan salah satunya fungsi penglihatan (Hardriani, 2016). Hasil penelitian sebuah lembaga riset menyebutkan bahwa Indonesia berada di peringkat kelima dalam daftar pengguna smartphone terbesar di dunia dengan pengguna aktif sebanyak 47 juta atau sekitar $14 \%$ dari seluruh total pengguna ponsel (Dediu, 2013).

Gadget dapat memengaruhi mata karena dapat menyebabkan banyak hal seperti kurangnya daya akomodasi, mata kering dan kelelahan mata. Kelelahan mata ini dapat terjadi karena pencahayaan yang kurang memadai. Selain itu, juga dapat dihasilkan dari stres intensif pada fungsi mata seperti terhadap otot akomodasi (Suma'mur, 2009). Menurut data terbaru, setidaknya 30 juta anak-anak dan remaja di Indonesia merupakan pengguna internet dan media digital saat ini menjadi pilihan utama saluran komunikasi yang mereka gunakan. Berdasarkan studi yang telah dilakukan oleh Kominfo pada anak-anak dan remaja usia 10-19 tahun ditemukan bahwa $98 \%$ dari anak-anak dan remaja yang 3 disurvei tahu tentang internet dan bahwa 79,5\% diantaranya adalah pengguna internet (RI, 2014). Anak-anak yang terbiasa menggunakan gadget untuk mengakses internet dan belajar dapat mengalami gangguan kesehatan pada mata mereka. Banyak anak yang matanya minus karena menggunakan gadget. Sekitar $80 \%$ anak yang menggunakan kacamata karena penggunaan teknologi dan informasi (Hardriani, 2016).

Diperkirakan gangguan refraksi menyebabkan 8 juta orang mengalami kebutaan atau $18 \%$ dari penyebab kebutaaan global. Prevalensi miopia memiliki kecenderungan meningkat pada usia anak anak dan dewasa. (American Academy of Ophtalmology, 2011). Kelainan refraksi memiliki prevalensi cukup tinggi di Indonesia, yaitu sebesar $24,7 \%$ dan pada anak-anak usia sekolah sebesar $10 \%$ dari 66 juta anak Indonesia (Djua, 2015). Pada tahun 2016, Rita Handriani melakukan penelitian tentang "Pengaruh Unsafe Action Penggunaan Gadget terhadap Ketajaman Penglihatan Siswa Sekolah Dasar Islam Tunas Harapan Semarang Tahun 2016". Penelitian tersebut didapatkan hasil pengaruh terbesar dalam menurunkan ketajaman penglihatan adalah posisi, lama waktu, dan jarak pandang saat menggunakan gadget sedangkan penerangan tidak memilik pengaruh yang berarti (Hardriani, 2016).

Bedasarakan latar belakang tersebut peneliti ingin mengetahui pengaruh penggunaan gadget terhadap kejadian miopia terhadap usia anak sekolah (4-17 tahun) di RSI Jemursari Surabaya dengan mencari tahu pengaruh posisi saat menggunakan gadget, jarak mata dengan gadget, lama penggunaan gadget, dan pencahayaan ruang saat menggunakan gadget.

\section{METODE PELAKSANAAN}

Jenis dan Rancang Bangun Penelitian: Penelitian ini adalah survei analitik dengan pendekatan cross sectional yang dilakukan di Poli Mata Rumah Sakit Islam Jemursari Surabaya.

Populasi Penelitian: Populasi ini adalah pasien anak usia sekolah (4-17 tahun) di Poli Mata Rumah Sakit Islam Jemursari Surabaya yang bersedia dilakukan penelitian. 
Sampel: Jumlah pasien anak usia sekolah (4-17 tahun) di Poli Mata Rumah Sakit Islam Jemursari Surabaya pada 5 bulan terakhir (bulan Mei, Juni, Juli, Agustus, dan September) adalah 326 pasien. Karena penelitian akan dilakukan selama satu bulan maka populasi dalam penelitian ini adalah rerata dari 5 bulan yakni 66. Banyaknya responden dalam penelitian ini adalah sebesar 31 orang. Kriteria inklusi: Pasien anak usia sekolah (4-17 tahun) di Poli Mata Rumah Sakit Islam Jemursari Surabaya yang terdiagnosis miopia, Bersedia menjadi subjek penelitian. Sedangkan kriteria ekslusi: Pasien anak usia 1-3 tahun di Poli Mata Rumah Sakit Islam Jemursari Surabaya yang terdiagnosis miopia.

Cara Pengambilan sampel: Cara pengambilan sampel dengan purposive sampling, dengan jumlah sesuai perhitungan besar sampel. Peneliti bekerjasama dengan petugas kesehatan di Poli Mata untuk menemukan responden yang sesuai kriteria. Responden dimintai mengisi kuesioner dengan apa adanya untuk meyakinkan agar data yang didapat objektif dan didampingi oleh peneliti. Selanjutnya peneliti akan mengumpulkan kuesioner yang sudah diisi oleh responden.

Pengumpulan Data dan Instrumen Penelitian: Jenis pengumpulan data pada penelitian ini menggunakan 2 jenis data yakni: 1. Data Primer yang diambil secara langsung oleh peneliti dengan cara memberikan kuesioner kepada subyek penelitian dan telah disetujui oleh orang tua subyek penelitian tersebut, karena subyek penelitian ini adalah anak usia sekolah (4-17 tahun). Pengisian 50 kuesioner akan didampingi oleh peneliti untuk meminimalisir adanya kriteria ekslusi. 2. Data Skunder yang didapatkan dari rekam medis penderita miopia yang dilakukan oleh dokter spesialis mata yang bertugas di Poli Mata RSI Jemursari Surabaya. Dalam penelitian ini peralatan yang digunakan untuk pengambilan data beserta pendukungnya adalah kuesioner dan rekam medis.

Pengolahan dan Analisis Data: Pengolahan data dilakukan dengan memasukkan data ke dalam program komputer Statistical Package for Social Science (SPSS). Analisis data pada penelitian ini adalah analitik multivariat dengan variabel dependennya kategorikal (nominal/ordinal) yang menggunakan uji regresi logistik ordinal dikarenakan variabel terikat dalam penelitian ini memiliki skala data nominal dan variabel bebas dalam penelitian ini memiliki skala data ordinal. Analisis data yang digunakan adalah uji Regresi logistik ordinal.

\section{HASIL DAN PEMBAHASAN}

Tabel 1

Gambaran Umum Responden

\begin{tabular}{llll}
\hline & & Frekuensi & Persentase (\%) \\
\hline Umur & & & \\
& 0-5 tahun & 1 & 3,2 \\
& 5-11 tahun & 14 & 45,2 \\
& 12-16 tahun & 16 & 51,6 \\
\hline Jenis Kelamin & & & \\
& Laki-laki & 14 & 45,2 \\
& Perempuan & 17 & 54,8 \\
\hline Jenjang Pendidikan & & & \\
& TK & 1 & 3,2 \\
& SD & 17 & 54,8 \\
& SMP & 11 & 35,5 \\
& SMA & 2 & 6,5 \\
\hline
\end{tabular}

Berdasarkan Tabel 1 diatas dapat diperoleh informasi bahwa sebagian besar responden berusia 12-16 tahun (51,6 \%), berjenis kelamin perempuan (54,8 \%), dan berada dijenjang pendidikan SD (Sekolah Dasar) $(54,8 \%)$.

Tabel 2

Gambaran Khusus Responden: Gambaran saat menggunakan gadget

\begin{tabular}{llll}
\hline & & Frekuensi & Persentase (\%) \\
\hline Tiduran & & & \\
& Tiduran & 19 & 61,3 \\
& Duduk & 12 & 38,7 \\
\hline Pencahayaan Ruang & & & \\
& Terang & 15 & 48,4 \\
& Redup & 16 & 51,6 \\
\hline
\end{tabular}




\begin{tabular}{llll} 
& Tidak Baik $(<30 \mathrm{~cm})$ & 14 & 45,2 \\
& Baik $(\geq 30 \mathrm{~cm})$ & 17 & 54,8 \\
\hline Lama Penggunaan & & & \\
& Cukup $(<2$ jam $)$ & 14 & 45,2 \\
& Berlebihan $(\geq 2$ jam $)$ & 17 & 54,8 \\
\hline
\end{tabular}

Berdasarkan Tabel 2 diatas dapat diperoleh informasi bahwa sebagian besar responden menggunakan gadget dengan posisi tubuh tiduran $(61,3 \%)$, hal tersebut sesuai dengan penelitian Ekawati dan Kulihana (2018) bahwa posisi tidur berbaring termasuk posisi yang sering disukai dalam penggunaan gadget dimana posisi tersebut termasuk katagori yang salah. Sebagian besar responden menggunakan gadget pada ruangan dengan pencahayaan yang redup $(51,6 \%)$, hal tersebut sesuai dengan penelitian yang dilakukan oleh Fitri (2017) bahwa jarak penggunaan gagdet usia sekolah cenderung kategori baik. Sebagian besar responden

\section{Tabel 3}

Gambaran Khusus Responden: Karakteristik Responden Berdasarkan Visus Penggunaan Gadget

\begin{tabular}{lrrr}
\hline \multicolumn{1}{c}{ Visus Penggunaan Gadget } & Frekuensi & Persentase (\%) \\
\hline Miopia Ringan & 17 & 54,8 \\
Miopia Sedang & 9 & 29,0 \\
Miopia Berat & 5 & 16,1 \\
\hline
\end{tabular}

Berdasarkan Tabel 3 diatas dapat diperoleh informasi bahwa sebagian besar responden $(54,8 \%)$ mengalami visus myopia ringan pasca menggunakan gadget. Perbedaan presentase derajat miopia tersebut bisa disebabkan karena perbedaan penyebab miopia oleh masing-masing responden. Hal tersebut didukung oleh menggunakan gadget dengan jarak pandang mata dan gadget $\geq 30 \mathrm{~cm}(54,8 \%)$, hal tersebut sesuai dengan penelitian Ermawati (2015) dan Handriani (2016) bahwa pada usia sekolah anak-anak cenderung menggunakan gadget secara berlebihan. Sebagian besar responden menggunakan gadget dengan durasi lama waktu penggunaan gadget selama $\geq 2$ jam $(54,8$ $\%$ ), hal tersebut sesuai dengan penelitian Djua (2015) dan Ermawati (2015) bahwa pencahayaan ruangan dalam menggunakan gadget paada usia sekolah lebih banyak dalam kondisi redup yang termasuk dalam kategori tidak baik. pernyataan Hayatillah (2011) bahwa tingkat keparahan miopia bisa disebabkan oleh faktor internal maupun eksternal oleh penderita, yang meliputi genetik, riwayat keluarga, anatomi mata penderita, kebiasaan dan pendidikan penderita.

Tabel 4

Beberapa Asumsi Dalam Pengujian Regresi Logistik Ordinal

\begin{tabular}{|c|c|c|c|c|}
\hline No. & Indikator & Nilai & Syarat & Keterangan \\
\hline 1 & Goodness od Fit & Sig $=0,635$ & $>0,05$ & Model layak digunakan \\
\hline 2 & Nagelkerke & 0,249 & & $\begin{array}{llr}\text { Persentase } & \text { Pengaruh } \\
\text { Variabel Bebas terhadap } \\
\text { Variabel Terikat sebesar } \\
24,9 \%\end{array}$ \\
\hline
\end{tabular}

Berdasarkan Tabel 4 diatas dapat diinformasikan bahwa untuk indikator Goodness od Fit menunjukkan model dalam penelitian ini, yaitu pengaruh penggunaan gadget terhadap kejadian myopia, telah sesuai dengan data empiris atau model layak untuk digunakan. Sedangkan indikator Nagelkerke menunjukkan bahwa variabel bebas (penggunaan gadget) mampu untuk menjelaskan variabel terikat (kejadian miopia) dengan persentase sebesar 63 $24,9 \%$. Sedangkan $75,1 \%$ mungkin disebabkan oleh sebab lain yang tidak diteliti oleh peneliti seperti adanya faktor internal yang meliputi genetik, usia, dan panjangn bola mata.

Tabel 5

Pengaruh Penggunaan gadget terhadap Kejadian Miopia

\begin{tabular}{|c|c|c|c|c|}
\hline No. & Variabel Bebas & Signifikansi & Syarat & Keterangan \\
\hline 1 & Posisi & 0,339 & $<0,05$ & Tidak berpengaruh signifikan \\
\hline 2 & Pencahayaan & 0,301 & & Tidak berpengaruh signifikan \\
\hline 3 & Jarak & 0,049 & & Berpengaruh signifikan \\
\hline
\end{tabular}




\begin{tabular}{|c|c|c|c|c|}
\hline No. & Variabel Bebas & Signifikansi & Syarat & Keterangan \\
\hline 4 & Lama & 0,239 & & Tidak berpengaruh signifikan \\
\hline
\end{tabular}

Berdasarkan Tabel 5 diatas, dapat diinformasikan bahwa dari keempat komponen penggunaan gadget, hanya variabel jarak yang memiliki pengaruh signifikan terhadap terjadinya miopia pada anak-anak. Sedangkan variabel lain seperti posisi tubuh, pencahayaan dan lama waktu yang dihabiskan dalam bermain gadget tidak berpengaruh signifikan terhadap terjadinya miopia. Hasil penelitian ini sesuai dengan penelitian yang dilakukan oleh Handriani (2016) bahwa terdapat hubungan jarak pandang penggunaan gadget dengan penurunan ketajaman (miopia). Menjaga jarak pada saat penggunaan gadget merupakan hal yang penting karena menjaga gaya akomodasi mata dalam melihat suatu obyek. Hasil penelitian ini sesuai dengan penelitian yang dilakukan oleh Fitri (2017) bahwa menjaga jarak pandang penggunaan gadget merupakan hal yang penting dalam menjaga aktifitas akomodasi mata. Penurunan ketajaman penglihatan (miopia) juga bisa disebabkan aktifitas melihat jarak dekat yang menyebabkan aktifitas akomodasi meningkat, karena makin dekat jarak obyek mata maka makin kuat mata berakomodasi (mencembung). Reflek akomodasi akan muncul jika mata melihat obyek dengan jarak dekat dan melihat benda yang kabur (Ilyas, 2017).

\section{Kesimpulan}

Sebagian besar responden menggunakan posisi tiduran, dengan jarak $\geq 30 \mathrm{~cm}$, dengan durasi $\geq 2$ jam,

\section{Daftar Rujukan}

1. American Academy of Ophtalmology, 2011. Retina and Vitreous, San Fransisco: Basic and Clinical Science Course: American Optometric Association (AOA).

2. Dediu, H., 2013. Intenet dan Seluk Beluknya. Jakarta: Gramedia Pustaka Utama.

3. Djua, N., 2015. Gambaran Faktor-Faktor yang Mepengaruhi Progresivitas Penderita Miopia di Poliklinik Mata RSUD Prof. DR. H. Aloei Saboe, Gorontalo: Universitas Negeri Gorontalo, Indonesia.

4. Ermawati, Budiharto \& Winarianti, 2015. Pengaruh Penggunaan Gadget Terhadap Penurunan Tajam Penglihatan pada Anak Usia Sekolah (6- 12 Tahun) di SD Muhammadiyah 2 Pontianak Selatan. Jurnal ProNers

5. Fitri, Trisna Ika. 2017. Hubungan Lama Penggunaan Dan Jarak Pandang Gadget Dengan Ketajaman Penglihatan Pada Anak dan menggunakan gadget pada ruangan dengan pencahayaan yang redup. Sebagian besar responden mengalami visus myopia ringan pasca menggunakan gadgetSebagian besar responden mengalami visus myopia ringan pasca menggunakan gadget. Dari keempat komponen penggunaan gadget, dapat diketahui bahwa hanya jarak yang memiliki pengaruh signifikan terhadap terjadinya miopia pada anak usia sekolah (4-17 tahun) di RSI jemursari. Sedangkan variabel lain seperti posisi tubuh, pencahayaan dan lama waktu yang dihabiskan dalam bermain gadget tidak berpengaruh signifikan terhadap terjadinya miopia pada anak usia sekolah (4-17 tahun) di RSI jemursari. Kepada pihak orang tua agar mengawasi serta memberikan edukasi kepada anaknya agar bisa mengurangi faktor resiko kejadian miopia karena penggunaan gadget, serta melakukan pemeriksaan kesehatan mata secara rutin. Pihak rumah sakit diharapkan memberikan pengetahuan tentang dampak buruk penggunaan gadget yang berlebihan dan memberikan pengetahuan tentang bagaimana cara memelihara mata agar tetap normal dan sehat.

\section{Ucapan Terima kasih}

Penulis mengucapkan terima kasih kepada R.A. Hani Faradis, dr., Sp. M, Andi Roesbiantoro, dr., Sp. THTKL, Hotimah Masdan Salim, dr., P.hD, David Sajid Muhammad dan Fakultas Kedokteran Universitas Nahdlatul Ulama Surabaya

Sekolah Dasar Kelas 2 Dan 3 di SDN 027 KOTA Samarinda

6. Hardriani, R., 2016. Pengaruh Unsafe Action Penggunaan Gadget terhadap Ketajaman Penglihatan Siswa Sekolah Dasar Islam Tunas Harapan Semarang Tahun 2016, Semarang: UDNUS.

7. Ilyas, S., 2017. Ilmu Penyakit Mata. 5 ed. Jakarta: Badan penerbit FKUI.

8. Kementrian Kesehatan RI, 2012. Mata Sehat di Segala Usia untuk Peningkatan Kualitas Hidup Masyarakat Indonesia, Jakarta: Pusat Komunikasi Publik Sekretariat Jendral Kementrian Kesehatan RI.

9. Suma'mur, 2009. Higiene Perusahaan dan Kesehatan Kerja Jakarta. Jakarta: CV Sagungseto.

10. Yu, 1. et al., 2011. Epidemiology, Genetics and Treatement for Miopia. Int $J$ Ophthalmol, 4(6), pp. 658-669. 